\title{
Clarificação de águas de lavagem de filtros em estações de tratamento de água por coagulação, floculação e flotação por ar dissolvido
}

\author{
Clarification of spent filter backwash water in water treatment plants by \\ coagulation, flocculation and dissolved air flotation
}

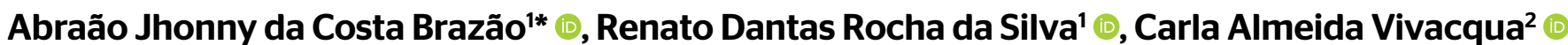

口-

\begin{abstract}
RESUMO
Este artigo apresenta estudos de coagulação, floculação e flotação por ar dissolvido que foram conduzidos com o objetivo de promover a clarificação de águas de lavagens de filtros (ALF) em uma estação de tratamento de água (ETA) com base em experimentos de bancada e piloto. A efetividade da coagulaçãofloculação foi analisada pela flotabilidade dos agregados obtidos sob diferentes níveis de $\mathrm{pH}$ e dosagem de cloreto de polialumínio, enquanto ensaios de flotação foram investigados com base na eficiência de saturação em bancada e na taxa de recirculação. Os resultados indicaram que o pH e a concentração do coagulante representaram condições críticas na etapa de coagulação. A variação do pH da ALF condicionada com 8 mg. L $^{-1}$ de $A l^{\dagger 3}$ destacou a formação de espécies hidrolisáveis e a elevada atividade das cargas dos coloides indicou a ocorrência de mecanismos diferentes da neutralização de cargas na coagulação. A máxima clarificação da água ocorreu com dosagem de 12 mg. $\mathrm{L}^{-1}$ de $\mathrm{Al}^{+3}$, razão de recirculação de 10\%, tempo de floculação de 15 min e pH 6,5. Em configuração otimizada, a técnicaalcançou remoção de 88\% deturbideze $86 \%$ de sólidos totais, o que pode resultar em mais de 11 quilogramas de sólidos removidos do sistema de tratamento em cada ciclo de lavagem em comparação com a sedimentação, implicando aumento de 33\% da carreira de filtração e, consequentemente, redução de custos e melhor desempenho da estação.
\end{abstract}

Palavras-chave: lavagem de filtros; cloreto de polialumínio; resíduos sólidos; microbolhas.

\begin{abstract}
This article presents studies on coagulation, flocculation and dissolved air flotation that were conducted with the aim of promoting the clarification of spent filter backwash water (SFBW) in a Water Treatment Plant (WTP) based on bench and pilot experiments. The effectiveness of coagulation-flocculation was analyzed according to the buoyancy of the aggregates obtained from different levels of $\mathrm{pH}$ and dosage of polyaluminium chloride, whereas flotation tests were investigated based on bench saturation efficiency and recirculation rate. According to the results, the $\mathrm{pH}$ and the concentration of the coagulant represented critical conditions in the coagulation. The $\mathrm{pH}$ variation of the SFBW conditioned with $8 \mathrm{mg}^{-\mathrm{L}^{-1}}$ of $\mathrm{Al}^{+3}$ highlighted the formation of hydrolyzable species, and the high activity of the colloid indicated the occurrence of different mechanisms for neutralization in the coagulation. The maximum clarification

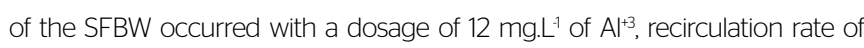
$10 \%$, flocculation time of $15 \mathrm{~min}$, and $\mathrm{pH}$ 6.5. In an optimized configuration, the technique achieved removal of $88 \%$ turbidity and $86 \%$ total solids, which can result in more than 11 kilograms of solids removed from the WTP in each backwashing cycle compared with sedimentation. This would imply an increase of $33 \%$ in the backwashing interval and, consequently, in the reduction of costs and in the better performance of the WTP.
\end{abstract}

Keywords: backwashing filters; polyaluminium chloride; solid waste: microbubbles.

\section{INTRODUÇÃO}

As estações de tratamento de água (ETA) são responsáveis por tornar a água in natura apta para o consumo humano mediante a obediência restrita a padrões de potabilidade impostos por legislações específicas. As operações e processos utilizados nessas estações concorrem para a geração de grandes volumes de resíduos, que se caracterizam como subprodutos do processo de tratamento (CHAVES, 2012).

Esses resíduos são formados pela agregação dos sólidos presentes na água bruta em associação aos produtos químicos adicionados ao processo de tratamento, sendo majoritariamente provenientes da limpeza dos decantadores (ou

IInstituto Federal de Educação, Ciência e Tecnologia do Rio Grande do Norte - Natal (RN), Brasil.

${ }^{2}$ Universidade Federal do Rio Grande do Norte - Natal (RN), Brasil.

*Autor correspondente: abraao.brazao@ifrn.edu.br

Conflitos de interesse: os autores declaram não haver conflito de interesses.

Financiamento: nenhum.

Recebido: 30/08/2018 - Aceito: 29/09/2020 - Reg. ABES: 20180112 
eventualmente dos flotadores) e da lavagem dos filtros (LUSTOSA et al., 2017). Em uma ETA convencional, a lavagem dos filtros é a etapa com maior geração de resíduos em termos volumétricos, enquanto a limpeza dos decantadores (ou flotadores) produz a maior quantidade em termos mássicos. Nas ETA que funcionam sob a concepção de filtração direta, o lodo é gerado pelos resíduos oriundos da lavagem dos filtros e pela sua descarga de fundo (FREITAS et al., 2010; LUSTOSA et al., 2017).

A água utilizada para a retrolavagem dos filtros, conhecida como água de lavagem dos filtros (ALF), pode representar cerca de 5\%, ou mais, do volume global de água tratada em uma ETA convencional (FREITAS et al., 2010). A ALF pode ter características variadas, a depender da qualidade apresentada pela água in natura e da tecnologia de tratamento adotada, dos produtos químicos utilizados e suas dosagens e do método de limpeza das unidades filtrantes. Na maioria dos casos, a ALF possui baixa concentração de sólidos ( 0,01 a $0,1 \%)$, flocos na forma de hidróxidos metálicos normalmente leves e com baixa velocidade de sedimentação, elevada umidade (>95\%) e geralmente sob a forma fluida (BOURGEOIS; WALSH; GAGNON, 2004; CHAVES, 2012; DI BERNARDO; DANTAS; VOLTAN, 2017).

Em função dos grandes volumes gerados e dos elevados custos de implantação e operação das estações de tratamento de resíduos (ETR), a prática comumente adotada no Brasil para o descarte da ALF tem sido o lançamento do resíduo sem tratamento em corpos aquáticos próximos às ETA, prática essa ilegal uma vez que a NBR 10004 (ABNT, 2004) classifica os lodos de ETA como resíduos sólidos e o lançamento in natura de tais resíduos no meio ambiente é vedado pela Política Nacional de Resíduos Sólidos (BRASIL, 2010).

Em razão da escassez crescente de mananciais com condições adequadas ao consumo humano, da tentativa de minimização de impactos ambientais e da busca pela economia da água, tem crescido o interesse pela recirculação da ALF para a linha de tratamento. Essa recirculação pode ser direta ou indireta, a depender da existência de tratamento prévio antes do retorno do resíduo à estação. Segundo Freitas et al. (2010), a prática da recirculação direta pode introduzir perigos no processo de tratamento, implicando riscos à saúde humana em virtude da presença de microrganismos que podem não ser retidos nos filtros e resistirem à etapa de desinfecção. Além disso, o encaminhamento direto da ALF para o início do tratamento pode recircular ferro, manganês, precursores dos tri-halometanos e outros elementos com potencial contaminante presentes na ALF (BOURGEOIS; WALSH; GAGNON, 2004). Dessa forma, a clarificação da ALF seguida pelo aproveitamento da fase líquida e destinação final dos sólidos apresenta-se como uma alternativa ambientalmente segura e tecnicamente viável para o resíduo em questão (USEPA, 2002).

As tecnologias utilizadas para o tratamento da ALF resumem-se basicamente na separação das fases líquidas e sólida, com o aumento da concentração dos sólidos no material sedimentado por clarificação, adensamento e desidratação, de maneira que seja possível o reúso do sobrenadante e a disposição final do material sedimentado (DI BERNARDO; DANTAS; VOLTAN, 2017). As lagoas de sedimentação são as unidades de tratamento mais utilizadas para a ALF, permitindo a clarificação, o adensamento e o desaguamento do lodo. Todavia, em função do elevado tempo de detenção requerido pelas lagoas, aumenta-se a possibilidade de alteração das propriedades do lodo, facilitando a liberação de contaminantes para o sobrenadante. Além disso, em função das grandes áreas de implantação, a proliferação de algas torna-se um problema comum para esse tipo de solução (DI BERNARDO; DANTAS; VOLTAN, 2017).
Entre as alternativas emergentes para o tratamento da ALF está a coagulação, promovida usualmente pelo uso de sais de alumínio ou ferro, seguida pela floculação e flotação por ar dissolvido (FAD). Diversos fatores podem interferir na etapa de coagulação, com destaque para a alcalinidade da água, a natureza e o tamanho das partículas coloidais e o tipo e a dosagem dos produtos químicos utilizados. Nesse sentido, o ajuste do nível ideal de pH e a dose do produto químico utilizado são condições reguladoras da eficiência do processo (LIBÂNIO, 2016). Complementar à etapa de coagulação, a floculação corresponde à agitação lenta responsável pela colisão das partículas anteriormente coaguladas, visando ao crescimento do floco e sua posterior remoção. Os parâmetros gradiente de velocidade e tempo de detenção hidráulico, além da eficiência de coagulação, constituem-se como os principais fatores intervenientes para essa etapa (LIBÂNIO, 2016).

$\mathrm{Na} F A D$, as partículas sólidas são removidas da fase líquida ao serem levadas a flutuar por meio da redução da sua densidade, com sua adesão a pequenas bolhas de ar. Nesse processo, as bolhas de ar são geradas pela súbita redução de pressão na corrente líquida saturada de ar, proveniente da câmara ou tanque de saturação. A otimização da FAD aplicada à clarificação de efluentes envolve o conhecimento dos fenômenos físico-químicos interfaciais, bem como dos mecanismos envolvidos na geração de bolhas e nas etapas de condicionamento e separação (TESSELE et al., 2005). A FAD apresenta vantagens quando comparada a sistemas de sedimentação, a destacar: maior adensamento do lodo, baixa sensibilidade à variação da vazão afluente, maior eficiência de clarificação da água e menor requisito de área em função do baixo tempo de detenção. Em contrapartida, a FAD requer mão de obra qualificada, manutenções com intervalos menores que as realizadas nas lagoas de decantação e maiores custos operacionais quanto ao consumo energético (TESSELE et al., 2005; CHAVES, 2012).

Este trabalho teve como objetivo investigar a técnica de coagulação associada à floculação e flotação por ar dissolvido (FAD) aplicada na clarificação de águas de lavagem de filtros (ALF) em estudo realizado em ETA localizada no município de Extremoz, região metropolitana da cidade de Natal (RN), no Nordeste brasileiro.

\section{METODOLOGIA}

\section{Cenário de investigação}

A ETA Extremoz, objeto de investigação neste estudo, é gerenciada e operada pela Companhia de Águas e Esgotos do Rio Grande do Norte (CAERN). Capta água da Lagoa de Extremoz, manancial pertencente à bacia hidrográfica do Rio Doce, com contribuições de águas subterrâneas e superficiais do Rio Guagiru ao sul e do Rio Mudo ao norte. A ETA, embora projetada e construída sob a concepção convencional (coagulação, floculação, decantação, filtração e desinfecção), atualmente funciona sob a concepção de filtração direta em função da desativação dos floculadores e decantadores, servindo estes apenas como câmaras de passagem. A mudança na forma de operação da ETA foi assumida pela companhia de águas em virtude da dificuldade na formação de flocos sedimentáveis provocada pela baixa turbidez da água bruta (FREITAS, 2017).

A retrolavagem dos filtros é realizada somente com água tratada na própria estação, e são gastos cerca de $155 \mathrm{~m}^{3}$ dessa água para cada um dos quatro filtros da ETA diariamente. A água residuária gerada pela lavagem dos filtros (denominada ALF) é bombeada até uma lagoa de sedimentação com volume 
útil de $5.000 \mathrm{~m}^{3}$ e $2.500 \mathrm{~m}^{2}$ de área superficial, onde, após período de detenção, $64 \%$ do volume afluente à lagoa é recirculado para a linha de alimentação das etapas de tratamento na ETA e $36 \%$ sofre processo de infiltração ou evaporação (BRITO; DUARTE; ARAÚJO, 2018).

\section{Estudos de coagulação-floculação-flotação em bancada}

Na primeira etapa da investigação, foram realizados ensaios de coagulação-floculação-flotação em bancada para a definição da concentração de cloreto de polialumínio (CPA) a ser investigada nos experimentos na unidade piloto. Sete doses de CPA comercial ( 18 a 23\% $\mathrm{Al}_{2} \mathrm{O}_{3}$, Beraca S/A) com variação de 0 a $15 \mathrm{mg}$ de $\mathrm{Al}^{+3} \cdot \mathrm{L}^{-1}\left(0,2,4,6,8,10\right.$ e $\left.15 \mathrm{mg} \cdot \mathrm{L}^{-1}\right)$ foram experimentadas em estudos de bancada, sendo a escolha dessas concentrações iniciais baseada em estudos realizados por investigações antecedentes (FREITAS, 2017) conduzidas com a ALF da mesma ETA investigada nesta pesquisa. Para a realização desses ensaios, foram coletadas duas amostras de ALF com $20 \mathrm{~L}$ cada, coletas essas realizadas nos meses de outubro (Amostra 1) e novembro (Amostra 2) do ano de 2017. As amostras eram compostas por alíquotas (cerca de $4 \mathrm{~L}$ ) coletadas a cada minuto da lavagem dos filtros na ETA, sendo 5 min o tempo de lavagem total. As amostras foram obtidas durante a lavagem dos filtros em poço de visita localizado próximo dos filtros.

A ALF coletada foi submetida aos ensaios de coagulação-floculação-flotação com os parâmetros razão de recirculação, pressão de saturação, tempo de agitação e gradiente de velocidade na coagulação e floculação fixados para todas as doses testadas. Os tempos de mistura lenta (10 min) e rápida ( $2 \mathrm{~min}$ ) foram adotados baseados em estudos de coagulação realizados por Wimmer (2008), enquanto a pressão de saturação fixada (3,92 bar) atende às condições que garantem a saturação de volume de ar suficiente para a geração de microbolhas com tamanho adequado à flotação (2,5 - 5,0 bar) (RODRIGUES, 2004; DI BERNARDO; DANTAS; VOLTAN, 2017). A razão de recirculação inicialmente adotada (10\%) foi determinada em função de estudos realizados por Aisse et al. (2001), nos quais se obtiveram altas eficiências na remoção de turbidez, sólidos suspensos, matéria orgânica e fósforo, com razões de recirculação de 10 e $20 \%$.

Um flotateste de bancada, composto de um vaso saturador com capacidade de $4 \mathrm{~L}$ e uma célula de flotação graduada com capacidade para $1 \mathrm{~L}$ fabricada em material acrílico, foi utilizado nesta investigação. Para a alimentação do vaso saturador, empregou-se um compressor de ar modelo Pro Schulz Profissional CSV 10-2 HP, enquanto para as misturas rápida e lenta nas etapas de coagulação e floculação, respectivamente, adotou-se um agitador magnético. A Figura 1 apresenta um esquema do flotateste e demais equipamentos utilizados.

Os ensaios foram realizados com $1 \mathrm{~L}$ da ALF coletada para cada dose de coagulante investigada e o CPA utilizado foi fornecido pela companhia de águas do estado (CPA 18 a 23\% $\mathrm{Al}_{2} \mathrm{O}_{3}$, Beraca S/A). Os testes foram realizados para as duas amostras coletadas, sem repetições. A verificação das melhores doses do coagulante foi baseada na comparação da ALF antes e depois da aplicação da coagulação-floculação-FAD quanto aos parâmetros associados à presença de partículas sólidas na água de estudo (turbidez, cor aparente e sólidos totais).

\section{Ponto de carga zero}

O ponto de carga zero (PCZ) foi determinado para permitir a discussão acerca da influência da neutralização das cargas na formação dos flocos. O teste foi baseado no "experimento dos 11 pontos" apresentado por Deolin et al. (2013). Foram realizados dois testes para verificação da estabilidade de cargas entre a superfície dos sólidos presentes na água e os íons determinantes de potencial presentes no seio da solução $\left(\mathrm{H}^{+}\right.$e $\left.\mathrm{OH}^{-}\right)$. A primeira série experimental foi conduzida sem o uso de CPA e a segunda com a dosagem de 8 mg.L.- (melhor condição de coagulação observada nos estudos de bancada). O procedimento consistiu no ajuste inicial do $\mathrm{pH}$ da ALF para os valores 3, 4, 5, 6, 7, 8, 9 e 10 (8 pontos) com o uso de soluções de $\mathrm{HCl}$ ou $\mathrm{NaOH} 0,1 \mathrm{M}$. Após 24 horas de equilíbrio em banho termostático sob rotação constante de $30 \mathrm{RPM}$, o pH final das amostras foi registrado. $\mathrm{O} \mathrm{PCZ}$ correspondeu à faixa na qual o $\mathrm{pH}$ se manteve constante, independentemente do $\mathrm{pH}$ inicial $\left(\mathrm{pH}_{\text {final }}-\mathrm{pH}_{\text {inicial }}=0\right)$, ou seja, o pH no qual a superfície se comportou como um tampão. Os testes foram realizados em duplicata.

\section{Verificação da eficiência de saturação}

No intuito de investigar a precipitação de ar desprendida do sistema FAD após a saturação do ar com diferentes pressões, um sistema de determinação da eficiência de saturação foi desenvolvido neste trabalho. O sistema baseia-se nos métodos desenvolvidos por Bratby e Marais (1975), e sua configuração permite determinar o volume de ar desprendido para determinado volume de água saturada alimentada no sistema. A Figura 2 ilustra a configuração da unidade montada em laboratório. Os resultados foram expressos pela relação entre o volume de ar desprendido e aprisionado na coluna "B" e o volume de água que transborda no recipiente "C". A eficiência de saturação foi determinada pela Equação 1 .

$\mathrm{Ef}_{\mathrm{ar}}(\%)=\left(\frac{\mathrm{V}_{1}}{\mathrm{~V}_{2}} \frac{\mathrm{X}_{\mathrm{H}}}{}\right){ } 10 \mathrm{C}$

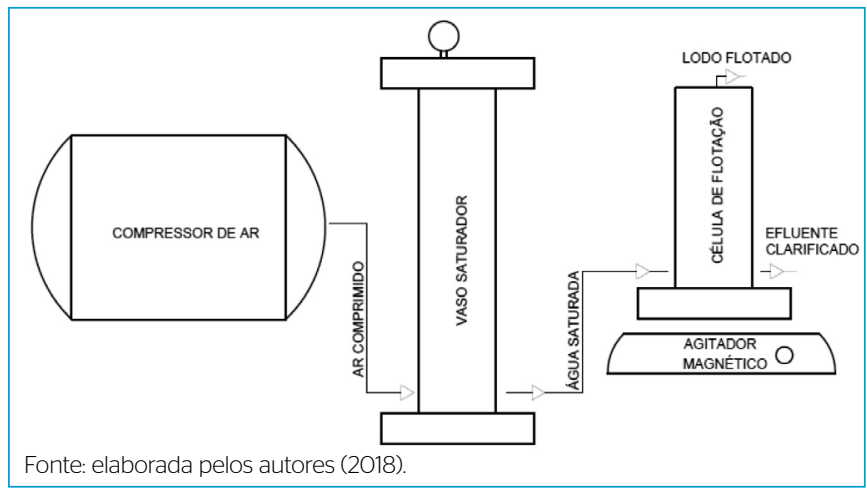

Figura 1 - Esquema do sistema de flotação por ar dissolvido de bancada: Flotateste, compressor de ar e agitador magnético.

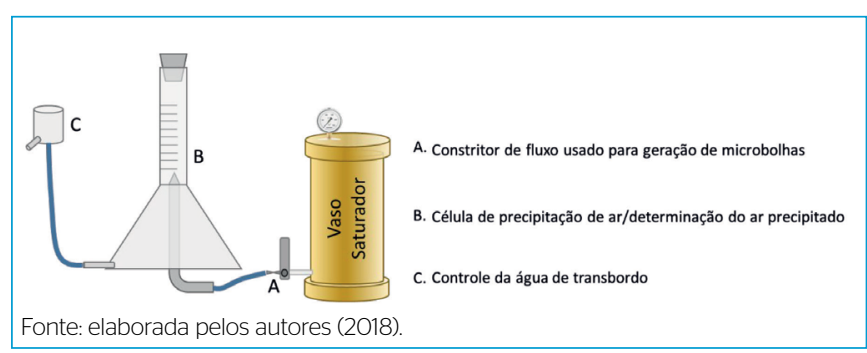

Figura 2 - Sistema de determinação da eficiência de saturação de ar em água. 
Em que:

$\mathrm{V}_{1}$ : volume de ar desprendido na coluna B após a despressurização da água saturada por válvula agulha;

$\mathrm{V}_{2}$ : volume de água inserida no sistema que transborda para o recipiente C;

$\mathrm{X}_{\mathrm{H}}$ : volume de ar teórico dissolvido em água na pressão de saturação específica do experimento.

\section{Estudos de coagulação-floculação-flotação na unidade piloto}

Os ensaios realizados em unidade de FAD alimentada por batelada instalada adjacente à ETA foram planejados com o intuito de investigar as condições operacionais para maximizar a clarificação da ALF. Para isso foram testados os fatores $\mathrm{pH}$, tempo de floculação, razão de recirculação e dose de coagulante.

Para o desenvolvimento dos experimentos de coagulação-floculação-flotação na unidade piloto, as amostras foram coletadas semanalmente entre o período de abril e junho de 2018. Para as coletas, foi utilizada uma bomba submersa portátil conectada a uma mangueira com sucção diretamente no filtro, em região próxima à calha coletora de ALF. Os ensaios na unidade piloto foram realizados com amostras de $2 \mathrm{~L}$ em cada célula de flotação e o $\mathrm{pH}$ foi ajustado com o uso de ácido sulfúrico $0,1 \mathrm{M}$ ou hidróxido de sódio $0,1 \mathrm{M}$, de acordo com o planejamento experimental.

Após a aplicação da FAD, as amostras eram armazenadas em recipiente de polietileno e conduzidas ao laboratório, onde eram realizadas as análises físico-químicas para a avaliação da eficiência de clarificação, sendo para isso analisados $\mathrm{pH}$, turbidez, cor aparente, sólidos totais, sólidos em suspensão totais e alcalinidade. Destaca-se que amostras de água clarificada por sedimentação foram coletadas e analisadas com o intuito de comparar a qualidade do efluente final tratado por FAD e sedimentação. A coletas eram compostas de amostras de $1 \mathrm{~L}$ e foram realizadas semanalmente entre o período de abril e junho de 2018, no ponto de descarga da água recirculada no canal de alimentação dos floculadores. As amostras foram submetidas aos testes de $\mathrm{pH}$, turbidez, cor aparente, sólidos totais, sólidos em suspensão totais e alcalinidade.

O flotateste instalado na ETA era composto de três colunas de flotação com capacidade de $5 \mathrm{~L}$ cada e uma câmara de saturação com capacidade de $4 \mathrm{~L}$, todas construídas em acrílico. Para a alimentação do vaso saturador, foi utilizado um compressor de ar portátil modelo Twister CSA 7,8-20 1,5 HP. A estrutura do flotateste continha ainda um motor que movimentava as três hastes metálicas (uma para cada coluna de flotação) acionado por um inversor de frequência. A Figura 3 apresenta um esquema do flotateste empregado nos estudos de flotação.

A velocidade de rotação das paletas metálicas instaladas nas colunas de flotação foi aferida com o uso de tacômetro. Os gradientes de velocidade para as misturas lenta e rápida foram obtidos por meio da equação de Ritcher (2009) e corresponderam a $63 \mathrm{~s}^{-1}$ e $776 \mathrm{~s}^{-1}$, respectivamente. Com base nos estudos de bancada para verificação da eficiência de saturação e na recomendação de Di Bernardo, Dantas e Voltan (2017), foi adotada a pressão de saturação de 5 bar para os testes na unidade piloto. Os níveis de dose de coagulante foram determinados em função dos estudos em bancada, ao passo que os demais ( $\mathrm{pH}$, razão de recirculação e tempo de floculação) foram estabelecidos em função de estudos realizados por Aisse et al. (2001) e Wimmer (2008).

\section{Planejamento dos experimentos e tratamento estatístico}

Em função dos objetivos da pesquisa e dos estudos realizados em bancada, o planejamento experimental envolveu os fatores $\mathrm{pH}$ e dose de coagulante em três níveis $(-1,0,+1)$ e razão de recirculação e tempo de floculação em dois níveis $(-1$ e +1$)$. A Tabela 1 apresenta os valores para cada nível adotado na pesquisa.

Os ensaios foram realizados em duplicata, agregados de acordo com o fator $\mathrm{pH}$ e planejados em fatorial completo utilizando o critério $\mathrm{k}^{\mathrm{n}}$, em que " $\mathrm{k}$ " representa o número de níveis e " $\mathrm{n}$ " o número de fatores, o que resultou, para a presente pesquisa, em 72 ensaios $\left(3^{2} \times 2^{2} \times 2\right.$ réplicas). Para cada coleta semanal de ALF (aproximadamente $20 \mathrm{~L}$ ), foram ensaiadas nove configurações diferentes na unidade piloto.

A análise dos resultados foi realizada com base em estatística descritiva, com o auxílio de gráficos e tabelas. Além disso, foram elaborados gráficos de efeitos principais para a verificação da contribuição dos parâmetros na clarificação da ALF. A função desejabilidade (desirability function) foi empregada para a determinação das configurações ótimas (JEONG; KIM, 2009; FITRIANTO; MIDI, 2012; ŞIMŞEK; TANSEL İÇ; ŞIMŞEK, 2013). Diagramas de caixas (boxplots) e teste $t$ foram elaborados com o intuito de comparar a FAD com a sedimentação. As análises estatísticas deste trabalho foram realizadas com o auxílio do software MINITAB 18 e R Studio, versão 1.2.1355.

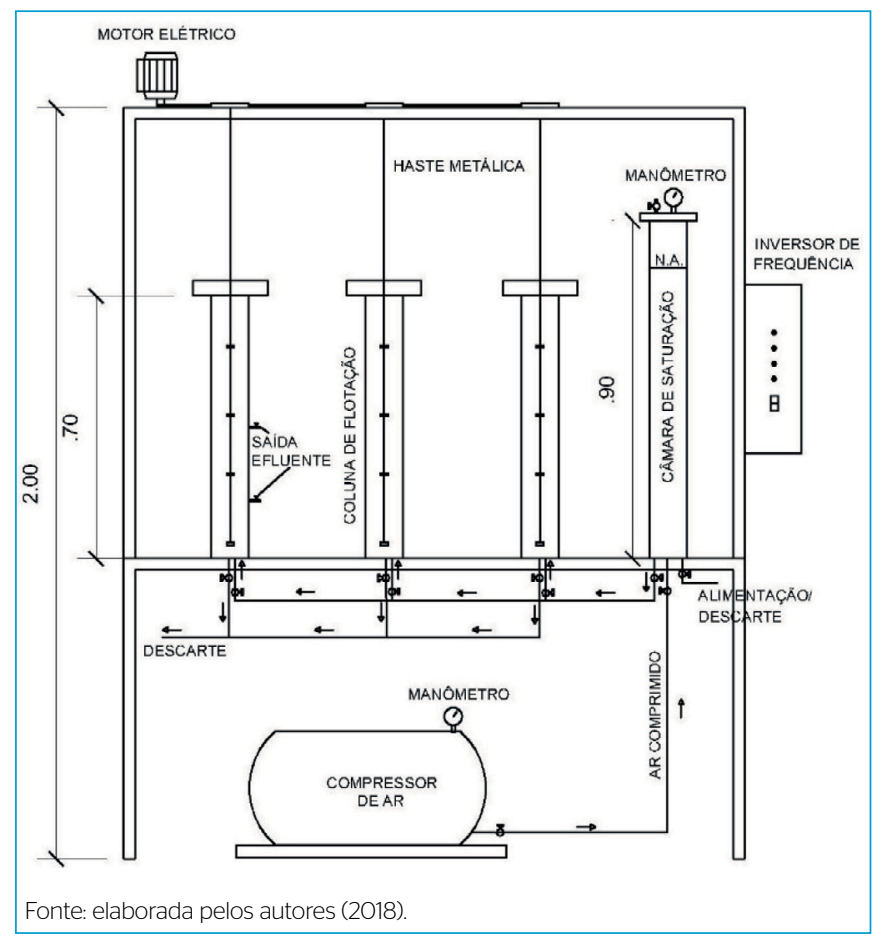

Figura 3 - Esquema do sistema de flotação por ar dissolvido instalado na estação de tratamento de água Extremoz.

Tabela 1 - Variáveis controladas no processo de coagulação-floculação-flotação.

\begin{tabular}{l|c|c|c}
\multirow{2}{*}{ Variável } & \multicolumn{3}{|c}{ Niveis } \\
\cline { 2 - 4 } & -1 & 0 & +1 \\
$\mathrm{nH}$ & 6,0 & 6,5 & 7,0 \\
\hline Dose de coagulante (mg/L) & 8,0 & 10,0 & 12,0 \\
\hline Razão de recirculação (\%) & 10 & - & 20 \\
\hline Tempo de floculação (min) & 10 & - & 15 \\
\hline
\end{tabular}




\section{RESULTADOS E DISCUSSÃO}

\section{Estudos de bancada}

A Tabela 2 apresenta a caracterização da ALF coletada para os estudos de coagulação em bancada. Os resultados indicaram que não houve grande flutuação nas características físico-químicas da ALF para o período estudado em razão do pequeno intervalo entre as coletas. Apenas houve destaque quanto ao aumento dos sólidos totais e cloretos na Amostra 2 em virtude do excedente de CPA utilizado na etapa de coagulação na ETA.

A investigação do efeito da concentração de alumínio trivalente $\left(\mathrm{Al}^{+3}\right)$ na clarificação da água de lavagem para as duas amostras foi conduzida em sistema de bancada. Os resultados dos parâmetros físico-químicos de qualidade da água analisados após coagulação-floculação-FAD da Amostra 1 estão reunidos na Tabela 3, enquanto os resultados analisados após coagulação-floculação-FAD da Amostra 2 estão reunidos na Tabela 4.

Tabela 2 - Características da água de lavagem de filtros coletada para os estudos de coagulação em bancada.

\begin{tabular}{l|c|c}
\hline Parâmetro & Amostra 1 & Amostra 2 \\
\hline $\mathrm{pH}\left(-\log \left[\mathrm{H}^{+}\right]\right)$ & 6,95 & 6,87 \\
\hline Turbidez (UT) & 89,00 & 86,60 \\
\hline Cor aparente $(\mathrm{UC})$ & 229,00 & 161,00 \\
\hline Sólidos totais $\left(\mathrm{mg} \cdot \mathrm{L}^{-1}\right)$ & 120,00 & 453,11 \\
\hline Cloretos $\left(\mathrm{mg} . \mathrm{L}^{-1} \mathrm{Cl}\right)$ & 22,99 & 41,98 \\
\hline Alcalinidade $\left(\mathrm{mg} \cdot \mathrm{L}^{-1} \mathrm{CaCO}_{3}\right)$ & 37,30 & 37,30 \\
\hline
\end{tabular}

Fonte: elaborada pelos autores (2018).
Pelos resultados obtidos, observa-se que houve redução dos parâmetros turbidez, cor aparente e sólidos totais à medida que se incrementou a dose de CPA. Na Amostra 1, o melhor resultado foi obtido na dosagem de $8 \mathrm{mg} \cdot \mathrm{L}^{-1}$ para os três parâmetros analisados. Essa constatação está de acordo com o observado por Freitas (2017) em estudos de jarteste com a ALF da mesma ETA investigada nesta pesquisa, onde a coagulação com CPA na dose de $8 \mathrm{mg} . \mathrm{L}^{-1}$ resultou na melhor condição analisada.

Estudos conduzidos por Silva (2011) destacam que a concentração de cátions metálicos de alumínio associada ao nível de $\mathrm{pH}$ da solução são aspectos determinantes para a definição dos mecanismos envolvidos na agregação de partículas em água. Nos experimentos conduzidos com a Amostra 1 , foi constatado que dosagens de $\mathrm{Al}^{+3}$ superiores a $8 \mathrm{mg} \cdot \mathrm{L}^{-1}$ promoveram redução de eficiência. Os cátions metálicos funcionam como contraíons que são responsáveis pela compensação das cargas superficiais das partículas e pela compressão da dupla camada elétrica que circunda a partícula coloidal (BRATBY, 2006). Contudo, concentrações excessivas dos cátions podem promover a inversão de cargas virtuais na superfície das partículas, impedindo sua agregação por neutralização de cargas (METCALF E EDDY, 2003; RODRIGUES, 2010).

Todos os resultados obtidos na coagulação indicaram decréscimo de $\mathrm{pH}$ após a adição de CPA na ALF. A acidificação da solução na presença de coágulos gerados com CPA indicou o forte consumo de íons hidroxila do seio da solução e a formação de hidróxidos metálicos responsáveis pela coagulação do sistema particulado na ALF. Esses resultados demonstraram que mecanismos aditivos à neutralização de cargas predominaram no sistema investigado (METCALF E EDDY, 2003).

Tabela 3 - Resultado dos parâmetros analisados após coagulação-floculação-flotação por ar dissolvido na Amostra 1. Pressão de 3,92 bar e taxa de reciclo de 10\%.

\begin{tabular}{|c|c|c|c|c|c|c|c|}
\hline \multirow{2}{*}{ Parâmetro } & \multicolumn{7}{|c|}{ Dosagem de CPA (mg. $\left.\mathrm{L}^{-1}\right)$} \\
\hline & 0 & 2 & 4 & 6 & 8 & 10 & 15 \\
\hline $\mathrm{pH}\left[\mathrm{H}^{+}\right]$ & 7,13 & 7,22 & 7,08 & 7,04 & 6,82 & 7,02 & 6,56 \\
\hline Turbidez (UT) & 7,1 & 7,7 & 4,2 & 2,1 & 0,2 & 0,5 & 1,4 \\
\hline Cor aparente (uC) & 36 & 32 & 27 & 18 & 10 & 11 & 13 \\
\hline Sólidos totais (mg.Lำ) & 720,00 & 100,00 & 80,00 & 20,00 & 20,00 & 140,00 & 180,00 \\
\hline Cloretos (mg. $\mathrm{L}^{-1} \mathrm{Cl}$ ) & 29,99 & 26,99 & 30,99 & 28,99 & 26,99 & 20,99 & 21,64 \\
\hline Alcalinidade $\left(\mathrm{mg}^{-1} \mathrm{~L}^{-1} \mathrm{CaCO}_{3}\right)$ & 49,18 & 47,21 & 49,18 & 51,14 & 23,60 & 37,37 & 21,64 \\
\hline
\end{tabular}

Fonte: elaborada pelos autores (2018).

Tabela 4 - Resultado dos parâmetros analisados após coagulação-floculação-flotação por ar dissolvido na Amostra 2. Pressão de 3,92 bar e taxa de reciclo de 10\%.

\begin{tabular}{|c|c|c|c|c|c|c|c|}
\hline \multirow{2}{*}{ Parâmetro } & \multicolumn{7}{|c|}{ Dosagem de CPA (mg. $\left.\mathrm{L}^{-1}\right)$} \\
\hline & 0 & 2 & 4 & 6 & 8 & 10 & 15 \\
\hline $\mathrm{pH}\left[\mathrm{H}^{+}\right]$ & 6,82 & 6,91 & 6,87 & 6,93 & 6,85 & 6,85 & 6,62 \\
\hline Turbidez (uT) & 13,4 & 12,3 & 5,3 & 3,8 & 2,7 & 1,7 & 1,9 \\
\hline Cor aparente (uC) & 82 & 72 & 65 & 38 & 30 & 20 & 21 \\
\hline Sólidos totais (mg. L'1) & 341,40 & 282,62 & 294,71 & 242,25 & 83,41 & 89,70 & 20,42 \\
\hline Cloretos (mg. $\left.\mathrm{L}^{-1} \mathrm{Cl}\right)$ & 43,98 & 45,98 & 54,98 & 59,98 & 61,98 & 51,98 & 66,97 \\
\hline Alcalinidade (mg.L.'- $\mathrm{CaCO}_{3}$ ) & 53,11 & 57,04 & 53,11 & 51,14 & 55,08 & 53,11 & 53,14 \\
\hline Condutividade elétrica ( $\mu \mathrm{S} . \mathrm{cm}^{-1}$ a $\left.25^{\circ} \mathrm{C}\right)$ & 286,7 & 265,8 & 267,4 & 275,9 & 269,9 & 274,3 & 285,6 \\
\hline
\end{tabular}

CPA: concentração de cloreto de polialumínio. Fonte: elaborada pelos autores (2018). 


\section{Ponto de carga zero}

Os experimentos para a determinação do ponto de carga zero desenvolvidos neste trabalho foram conduzidos no intuito de investigar a interação das partículas presentes na ALF com os íons determinantes de potencial do seio da solução e compreender, com base nesse aspecto, o grau de neutralização das cargas de superfície provocado pela dosagem do CPA.

Os resultados são apresentados na Figura 4 e indicam que as partículas presentes na ALF apresentavam carga de superfície neutra em $\mathrm{pH}$ próximo a 6,5 , indicando uma propensão à agregação por neutralização de cargas nessa faixa de pH. Em contraste, após a adição de CPA na concentração de $8 \mathrm{mg} \cdot \mathrm{L}^{-1}$, a superfície dos coágulos apresentou forte atividade com a interação com os íons determinantes de $\mathrm{pH}$. Esse fenômeno pôde ser observado com maior intensidade na faixa de $\mathrm{pH}$ entre 4 e 5 em função da formação de espécies poliméricas complexas de alumínio (SILVA, 2011).

A acidificação da solução na presença de coágulos gerados com CPA indicou o forte consumo de íons hidroxila do seio da solução e a formação de hidróxidos metálicos responsáveis pela coagulação do sistema particulado na ALF. Esses resultados demonstraram que mecanismos aditivos à neutralização de cargas predominaram no sistema investigado. Os resultados foram validados em experimentos duplicata. A Figura 4 apresenta o perfil de interação de íons determinantes de potencial com cargas da superfície de partículas presentes na ALF em função do $\mathrm{pH}$.

Estudos desenvolvidos por Gonçalves, Piotto e Resende (1997) apontaram a presença do mecanismo de varredura em adição ao de adsorção-neutralização de cargas com o uso de sais de alumínio como coagulante em pesquisas realizadas com lodos de ETA. Segundo os autores, é necessária uma caracterização química detalhada do lodo para a identificação dos mecanismos de coagulação predominantes, mediante a quantificação de alumínio sob a forma de hidróxido no lodo. Costa, Viana e Coelho (2005) comentam que o mecanismo de varredura ocorre geralmente nas ETA de ciclo completo (convencionais), enquanto o de adsorção-neutralização é típico em ETA que funcionam sob a concepção de filtração direta. Os autores ainda comentam que os mecanismos de coagulação são capazes de gerar lodos com características diferentes. Dessa forma, o conhecimento dos mecanismos predominantes pode auxiliar na escolha da tecnologia mais adequada para o tratamento de lodos de ETA.

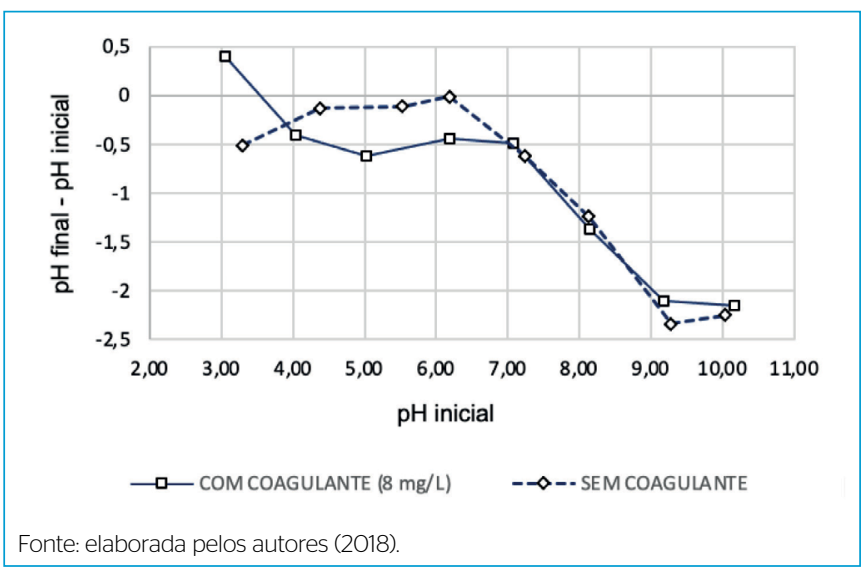

Figura 4 - Perfil de interação de íons determinantes de potencial com cargas da superfície de partículas presentes na ALF em função do pH.

\section{Verificação da eficiência de saturação}

Os resultados expressos na forma percentual de eficiência de saturação são mostrados na Tabela 5. Com base nos parâmetros de saturação estabelecidos pela lei de Henry, os resultados indicaram que há deficiência na etapa de geração de bolhas para o sistema de saturação investigado.

De acordo com a Lei de Henry, em determinada temperatura, uma máxima fração molar de gás dissolvido em água depende da sua pressão parcial exercida na fase líquida. Após o estágio de solubilização de ar em água sob pressões superiores às condições atmosféricas naturais, a água pressurizada é conduzida por um sistema de constrição de fluxo, em que o ar previamente saturado se desprende na forma de micro e nanobolhas (ETCHEPARE et al., 2017). A influência da ocorrência de nanobolhas na eficiência de mecanismos de adesão bolha-partícula tem sido mérito de investigações recentes (ETCHEPARE et al., 2017; AZEVEDO; OLIVEIRA; RUBIO, 2019). Em linhas gerais, a presença de nanobolhas em sistemas de FAD ocasiona a redução do tempo de indução do contato bolha-partícula e o incremento na estabilidade do agregado. Nesse sentido, a compreensão da influência da relação ar/sólido determina sensivelmente a eficiência de flotação de agregados floculados no tratamento de águas.

A eficiência desse sistema implica a garantia da etapa de interação bolha-partícula e da adequada relação ar/sólido na coluna de flotação, parâmetros operacionais determinantes em sistema de flotação aplicados ao tratamento de água (RODRIGUES, 2004; ETCHEPARE et al., 2017). Metcalf e Eddy (2016) destacam que relações ar/sólido comuns para sistemas de clarificação de efluentes líquidos ocorrem entre 0,005 e 0,060 ( $\mathrm{ml}$ ar/mg sólidos particulados ou em suspensão). Relações superiores representam desperdício de energia e pressurização excessiva nos sistemas de circulação da água, enquanto relações inferiores impedem que o volume de ar desprendido seja suficiente para sustentar a massa de sólidos presente nos sistemas floculados, comprometendo a clarificação eficiente da água (EDZWALD; HAARHOOF, 2012).

Em virtude do elevado teor de sólidos tipicamente presentes nas ALF, a eficiência do sistema de saturação de ar torna-se um aspecto determinante para que o ar desprendido do seio da solução consiga sustentar os sólidos.

Os resultados obtidos nesta pesquisa destacaram que valores médios de eficiência de saturação foram da ordem de $73 \%$ sob a temperatura de $27^{\circ} \mathrm{C}$. A variação da pressão alterou discretamente a eficiência de geração de bolhas, de modo que o aumento da pressão no vaso saturador justificou valores superiores de eficiência e maior rendimento energético, consequentemente. Outro aspecto determinante no incremento da eficiência justifica-se pelo aumento da velocidade do fluido no constritor de fluxo, sob variações de pressões maiores. Maior turbulência implica maior energia transferida para a água saturada com ar, garantindo o desprendimento da massa de ar dissolvida em água, na forma de microbolhas (FÉRIS; RUBIO, 1999). A pressão de saturação mantida em 3,92 bar (menor pressão investigada) já garantiu a relação ar/sólido proposta em sistemas típicos e em condições conservadoras que garantem a sustentação da carga de sólidos (METCALF E EDDY, 2016).

\section{Estudos na unidade piloto}

Para a análise da eficiência de tratamento por FAD, a ALF foi caracterizada conforme apresentado na Tabela 6.

Os resultados indicaram flutuação nas características físico-químicas da ALF, com destaque para cor aparente e sólidos totais. Essa flutuação ocorreu em virtude da variação das características da água in natura por influência direta 
da alteração de fatores climáticos, como incidência solar e precipitação pluviométrica, e das alterações das carreiras de filtração durante o período de estudo.

A Tabela 7 apresenta os resultados da análise global realizada na unidade piloto de FAD em função das eficiências de remoção dos parâmetros associados à clarificação escolhidos para a pesquisa.

Chaves (2012), em pesquisa realizada com a ALF tratada em uma unidade piloto de floco-flotação no estado do Ceará (Brasil), obteve 99,2\% de eficiência média na remoção de turbidez, $97,6 \%$ para cor aparente e $90,6 \%$ para sólidos suspensos. Os melhores resultados relativos à eficiência de tratamento apresentados pelos estudos conduzidos por Chaves (2012) podem ser explicados pela característica inicial da ALF. A carga de sólidos elevada induziu à percepção de valores percentuais de remoção superiores. Contudo, a análise final das características do efluente pós-flotação indicou concentração final de sólidos suspensos total em níveis médios de $15 \mathrm{mg} . \mathrm{L}^{-1}$, similar à do presente estudo, o que mostra a estabilidade do sistema de floculação-flotação para diferentes composições de efluentes.

Estudos conduzidos por Freitas et al. (2010) indicaram, ainda, que sistemas de decantação em coluna (alta taxa) são capazes de reduzir sólidos suspensos a níveis próximos de $90 \%$, similarmente aos resultados obtidos por sistemas

Tabela 5 - Parâmetros de eficiência de geração de bolhas em sistema de flotação por ar dissolvido.

\begin{tabular}{l|c|c|c|c} 
Pressão de & $\begin{array}{c}\text { Vol. ar/ } \\
\text { Voturação, bar } \\
\text { (Henry), } \\
\mathrm{mL}_{\mathrm{ar}} / \mathrm{L}\end{array}$ & $\begin{array}{c}\text { Valores ex- } \\
\text { perimentais } \\
\text { obtidos, } \\
\mathrm{mL}_{\mathrm{ar}} / \mathrm{L}\end{array}$ & $\begin{array}{c}\text { Eficiência } \\
\text { do sistema, } \\
\text { (\%) }\end{array}$ & $\begin{array}{c}\text { Relação ar/ } \\
\text { sólido (ml/ } \\
\mathrm{mg})^{*}\end{array}$ \\
\hline 3,92 & 72,1876 & 50 & 69 & 0,057 \\
\hline 4,9 & 90,2345 & 65 & 72 & 0,074 \\
\hline 5,88 & 108,2814 & 83,5 & 77 & 0,09 \\
\hline
\end{tabular}

*teor de sólidos suspensos pós-floculação considerado = 87,3 mg/l e relação de água saturada adicionada ao sistema de flotação = 10\%. Fonte: elaborada pelos autores (2018).

Tabela 6 - Caracterização da água de lavagem de filtros utilizada nos estudos na unidade piloto.

\begin{tabular}{|c|c|c|c|c|}
\hline Parâmetro & Mínimo & Média & Máximo & $\begin{array}{l}\text { Desvio } \\
\text { padrão }\end{array}$ \\
\hline $\mathrm{pH}\left(\mathrm{H}^{+}\right)$ & 6,2 & 6,5 & 7,0 & 0,30 \\
\hline Turbidez (UT) & 28 & 59 & 90 & 18,69 \\
\hline Cor aparente (uC) & 106 & 271 & 460 & 110,66 \\
\hline Sólidos totais (mg.Lำ) & 104 & 203 & 372 & 107,49 \\
\hline Sólidos suspensos totais (mg.L-1) & 64 & 74 & 88 & 7,87 \\
\hline Alcalinidade $\left(\mathrm{mg} \cdot \mathrm{L}^{-1} \mathrm{CaCO}_{3}\right)$ & 35 & 44 & 67 & 14,03 \\
\hline
\end{tabular}

Fonte: elaborada pelos autores (2018). de flotação. Contudo, tempos de residência superiores a 40 minutos e taxas de aplicação superficial limitadas a $1,3 \mathrm{~m}^{3} \cdot \mathrm{m}^{-2} \cdot \mathrm{h}^{-1}$ são necessárias. Esses resultados destacam a vantagem que sistemas de flotação apresentam quanto à capacidade de tratamento (small footprint) comparativamente aos sistemas de sedimentação, mesmo investigados em circuitos controlados de alta taxa.

Os resultados apresentados na Tabela 7 apontaram ainda aumento frequente na concentração de sólidos totais da ALF tratada por coagulação, floculação e flotação. Naturalmente, a solubilidade dos sais de alumínio (cloretos) aos níveis de $\mathrm{pH}$ investigados nos experimentos provocou um incremento na concentração final de sólidos totais da água tratada. Contudo, os valores médios de incremento aparentaram ser discretos e não resultaram em mérito de alteração do padrão de qualidade da água (BRASIL, 2017).

\section{Eficiências de remoção versus efeitos principais}

A Figura 5 apresenta os gráficos de efeitos principais para os fatores e níveis utilizados na pesquisa em função das eficiências médias de remoção para turbidez, cor aparente, sólidos suspensos totais e sólidos totais. Há um efeito principal quando diferentes níveis de um fator afetam a resposta de maneira diferente. Graficamente, isso acontece quando não se observa horizontalidade na linha representada. Quanto maior a inclinação da linha, maior é a magnitude do efeito principal. A linha de referência (tracejada) representa a média de eficiência global de remoção para o parâmetro em destaque.

Com base nos gráficos, pode-se observar que o $\mathrm{pH}$ foi o fator de maior influência na remoção de todos os parâmetros analisados (maior inclinação da linha em comparação aos demais fatores). Além do $\mathrm{pH}$, os outros fatores exerceram influência na clarificação da ALF, embora em menor magnitude (menor inclinação da linha), com destaque para a dose de coagulante.

Os gráficos também indicam que os níveis correspondentes às melhores remoções em um fator diferem a depender do parâmetro analisado, a exemplo do que acontece com o pH: a maior eficiência média de remoção para cor aparente e turbidez é observada no $\mathrm{pH} 6,5$, enquanto para sólidos suspensos totais e sólidos totais esse valor é obtido no pH 6,0. Em razão desse comportamento observado, a abordagem da função desejabilidade foi utilizada neste estudo.

Quanto aos demais fatores, as maiores eficiências médias de remoção foram obtidas na dose $12 \mathrm{mg} . \mathrm{L}^{-1}$, com exceção para o parâmetro sólidos totais $\left(8 \mathrm{mg} \cdot \mathrm{L}^{-1}\right)$, na razão de recirculação de $10 \%$ com exceção para o parâmetro turbidez $(20 \%)$, no tempo de floculação de 15 min para turbidez e cor aparente e no de 10 min para sólidos suspensos totais e sólidos totais.

Diante dessa variabilidade, valores individuais e globais da função desejabilidade foram calculados pelo software MINITAB 18 para a identificação da configuração com extração dos melhores resultados no sistema piloto. A clarificação máxima foi obtida na configuração correspondente a pH 6,5, dose de coagulante de 12 mg.L $\mathrm{L}^{-1}$, razão de recirculação de 10\% e tempo de floculação de 15 min.

Tabela 7 - Eficiências globais de remoção das variáveis de resposta utilizadas na pesquisa após a aplicação da flotação por ar dissolvido (\%).

\begin{tabular}{|c|c|c|c|c|c|c|c|}
\hline Parâmetro & Mínimo & $1^{0}$ quartil & Mediana & Média & $3^{\circ}$ quartil & Máximo & Desvio padrão \\
\hline Turbidez (UT) & 45 & 73 & 80 & 77 & 83 & 88 & 9,37 \\
\hline Cor aparente (uC) & 24 & 72 & 77 & 72 & 81 & 86 & 13,58 \\
\hline Sólidos totais (mg.L'1) & -273 & -64 & -10 & -22 & 33 & 83 & 60,88 \\
\hline Sólidos suspensos totais (mg.L'1) & 17 & 74 & 79 & 79 & 85 & 98 & 9,02 \\
\hline
\end{tabular}

Fonte: elaborada pelos autores (2018). 
(A)

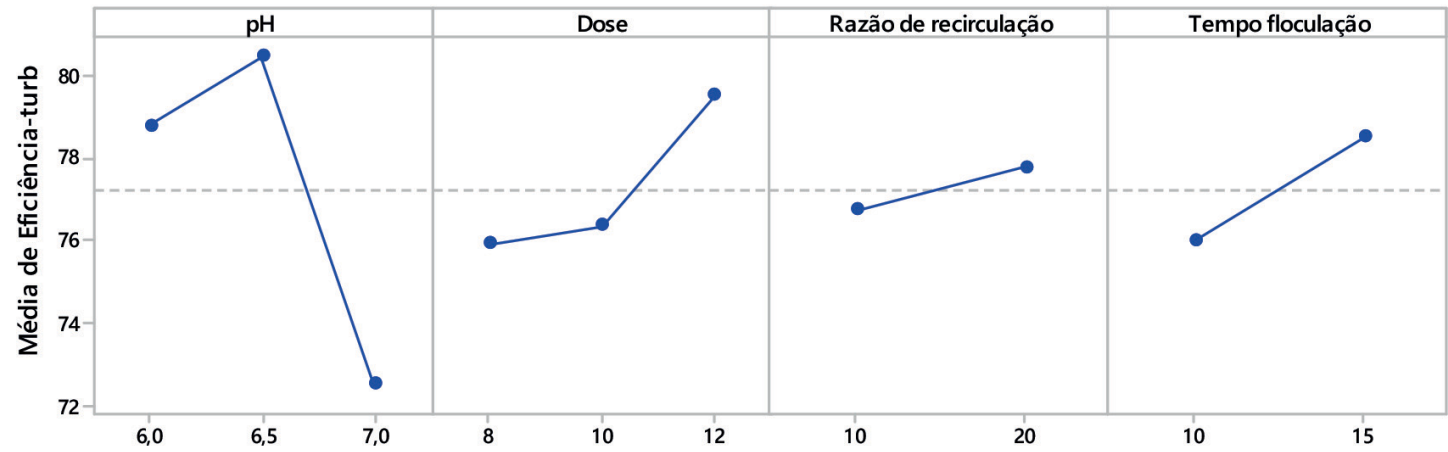

(B)

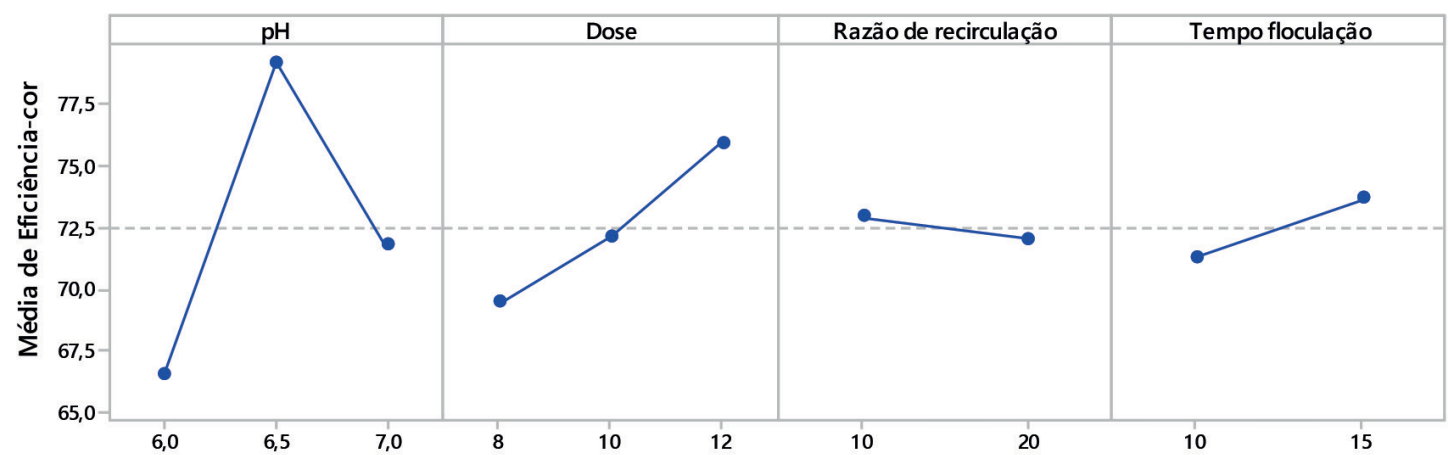

(C)

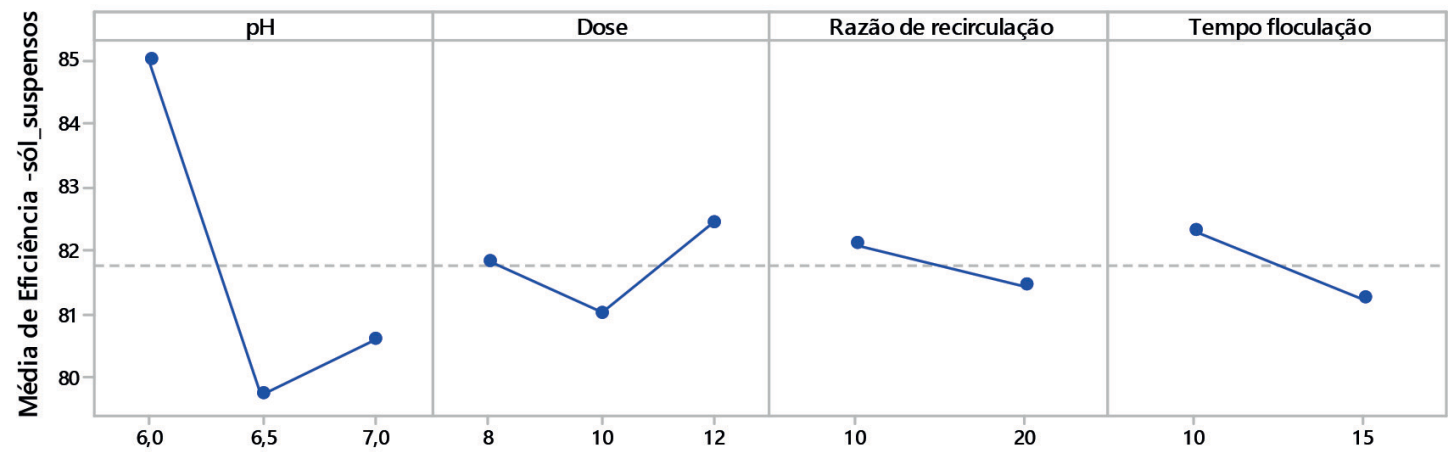

(D)

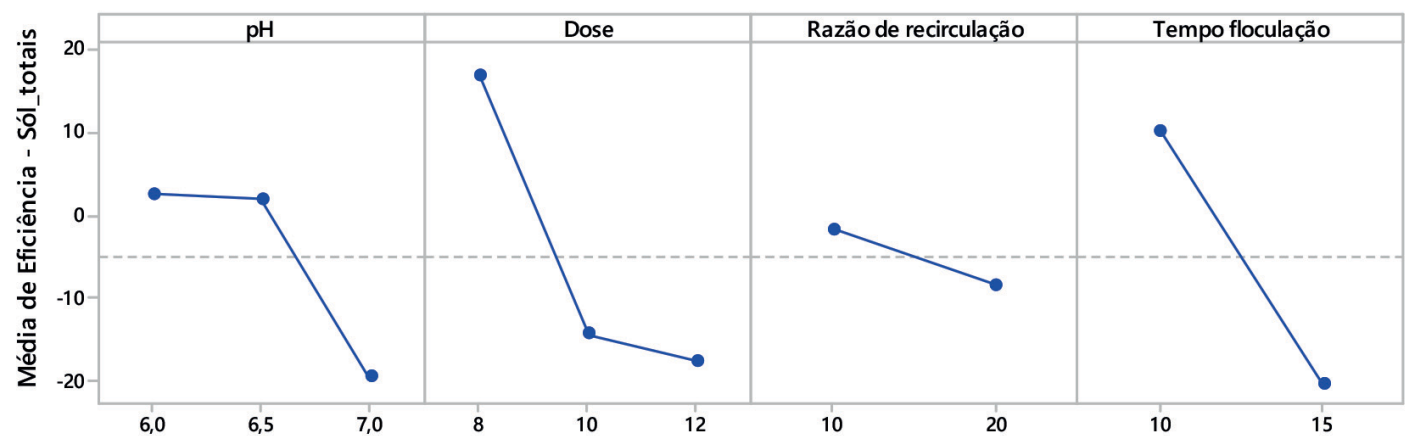

Fonte: elaborada pelos autores (2018).

Figura 5 - Efeitos principais para os níveis e fatores predeterminados em função das eficiências médias de remoção de (A) turbidez, (B) cor aparente, (C) sólidos suspensos totais e (D) sólidos totais. 


\section{Flotação x sedimentação}

A Tabela 8 apresenta as eficiências de remoção encontradas para a sedimentação realizada com a ALF na ETA investigada.

Torna-se evidente que o potencial da técnica de flotação aplicada no tratamento de ALF na ETA investigada promoveria sensíveis benefícios operacionais na operacionalização do tratamento. A Figura 6 traz os diagramas de caixas (boxplots) criados para comparar as eficiências de remoção encontradas para a sedimentação (diagrama direito) e a melhor configuração obtida para a FAD (diagrama esquerdo) para os parâmetros investigados na pesquisa.

Os diagramas da Figura 6 e as eficiências apontadas na Tabela 8 indicam que a eficiência média de remoção da configuração dos parâmetros operacionais ajustados obtida na FAD tende a ser superior em comparação com as eficiências médias encontradas na sedimentação para todos os parâmetros investigados, com destaque para turbidez e cor aparente. Os testes estatísticos para sólidos suspensos e sólidos totais foram inconclusivos pela presença de pontos discrepantes (outliers), enquanto os testes $t$ para turbidez e cor aparente corroboram diferença estatisticamente significante entre a configuração ótima de FAD e a sedimentação (valores p iguais a 0,00048 e 0,0043, respectivamente). A Tabela 9 apresenta o balanço de massa de sólidos totais e sólidos suspensos totais com base nas eficiências encontradas para a sedimentação (valores médios) e FAD (valores médios para a melhor configuração). Os cálculos foram baseados no volume de água tratada gasto para a lavagem de um filtro $\left(155 \mathrm{~m}^{3}\right.$ ) (BRITO;

Tabela 8 - Eficiências de remoção (\%) para a sedimentação.

\begin{tabular}{l|c|c|c|c|c|c|c}
\hline Parâmetro & Mínimo & 10 quartil & Mediana & Média & 30 quartil & Máximo & Desvio padrão \\
\hline Turbidez (uT) & 33 & 44 & 59 & 55 & 66 & 70 & 15,36 \\
\hline Cor aparente (uC) & 41 & 45 & 66 & 62 & 75 & 81 & 16,06 \\
\hline Sólidos totais (mg/L) & -211 & -10 & 11 & 4 & 64 & 95 & 96,62 \\
\hline Sólidos suspensos totais (mg/L) & 67 & 70 & 75 & 78 & 84 & 94 & 10,06 \\
\hline
\end{tabular}

Fonte: elaboração própria (2018).

(A)

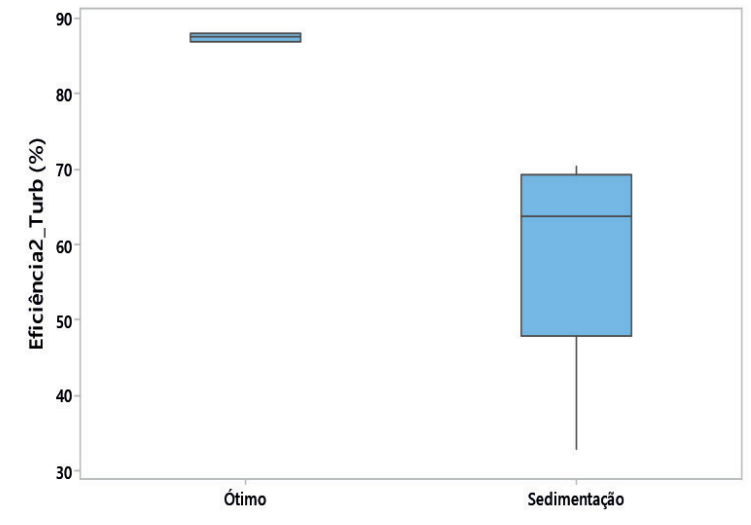

(C)

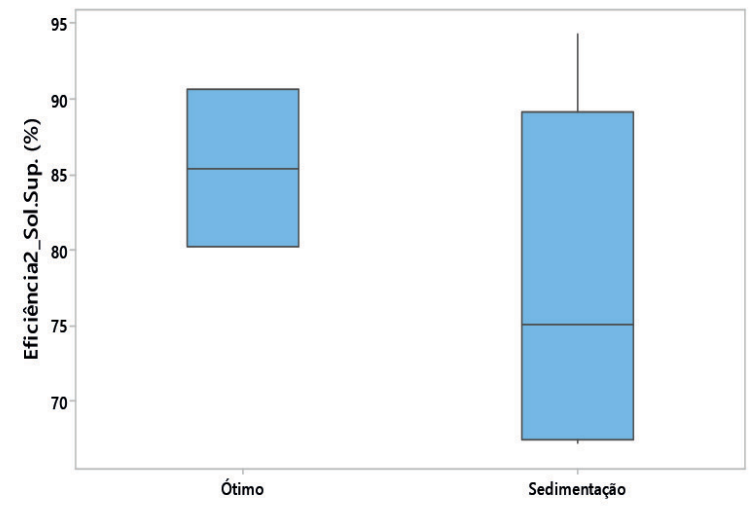

(B)

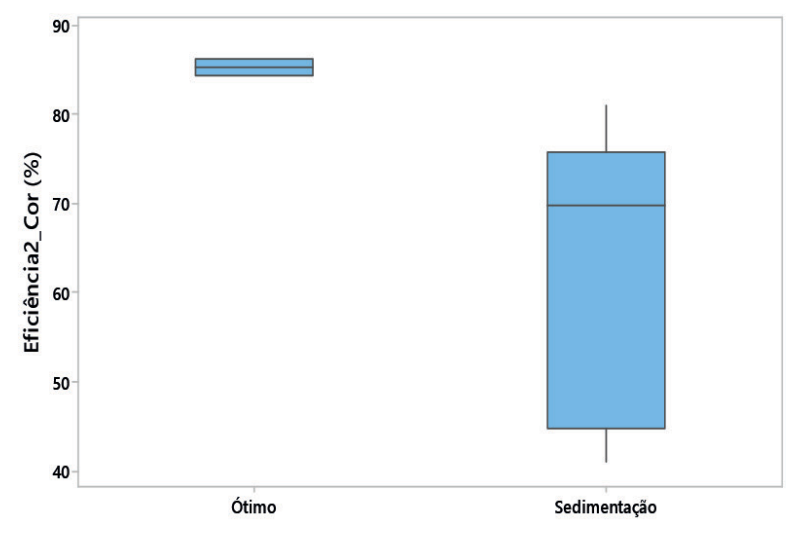

(D)

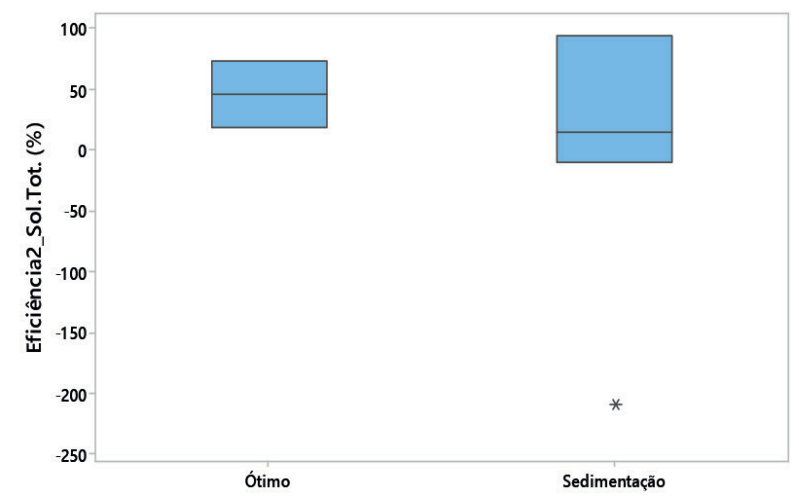

Fonte: elaboração própria (2018).

Figura 6 - Diagramas de caixas para as eficiências de remoção de (A) turbidez, (B) cor aparente, (C) sólidos suspensos totais e (D) sólidos totais obtidas na melhor configuração de flotação por ar dissolvido em comparação com a sedimentação. 
Tabela 9 - Balanço de massa de sólidos totais e suspensos totais para a lavagem de um filtro da estação de tratamento de água Extremoz.

\begin{tabular}{l|c|c|c|c|c|c}
\multirow{2}{*}{$\begin{array}{l}\text { Tecnologia/ } \\
\text { Parâmetro }\end{array}$} & \multicolumn{3}{|c|}{ Sólidos totais (kg) } & \multicolumn{3}{c}{ Sólidos suspensos totais (kg) } \\
\cline { 2 - 7 } & Afluente & Efluente & Remoção & Afluente & Efluente & Remoção \\
\hline Sedimentação & 31,5 & 30,2 & 1,3 & 11,5 & 2,5 & 8,9 \\
\hline FAD & 31,5 & 18,6 & 12,9 & 11,5 & 1,8 & 9,6 \\
\hline
\end{tabular}

Fonte: elaborada pelos autores (2018).

DUARTE; ARAÚJO, 2018) e nos dados de qualidade obtidos na caracterização da ALF (Tabela 6).

Os resultados mostram que a aplicação da FAD em configuração otimizada possibilitaria a redução de $11,6 \mathrm{~kg}$ de sólidos totais na alimentação dos sistemas dos filtros da ETA em comparação com a sedimentação, por processo unitário de lavagem, sendo, desse valor, $0,7 \mathrm{~kg}$ correspondente à parcela de sólidos suspensos totais. Essa redução implicaria o aumento da carreira de filtração em $33 \%$ para os filtros da ETA investigada, uma vez que o acúmulo dos sólidos retidos nos poros do leito filtrante é responsável pela diminuição da capacidade filtrante, ocasionando aumento da turbidez na água filtrada, aumento da perda de carga e consequente encerramento da carreira de filtração.

Não obstante, os insumos energéticos envolvidos nos sistemas de pressurização da FAD, ajustes mais rigorosos na dosagem de coagulantes e o controle prático dos sistemas de geração de bolhas (aspectos ausentes em sistemas convencionais de sedimentação) implicam a necessidade de operadores de ETA qualificados, para que os sistemas de flotação sejam explorados de maneira eficaz. Ademais, ajustes de infraestrutura no layout das ETA tradicionalmente dimensionadas no Brasil para sistemas de floculação/decantação e filtração representaria investimentos importantes para as companhias e empresas que gerenciam essas ETA.

Destacadamente, os benefícios do incremento na clarificação da água observados neste estudo e a maior taxa de aplicação superficial do sistema (cerca de sete vezes maior para a flotação em comparação com a sedimentação convencional para o estudo piloto conduzido neste trabalho $-12 \mathrm{~m}^{3} \cdot \mathrm{m}^{-2} \cdot \mathrm{h}^{-1}$ contra $1,65 \mathrm{~m}^{3} \cdot \mathrm{m}^{-2} \cdot \mathrm{h}^{-1}$ ) garantem (ou garantiriam) o tratamento de maior volume de água nas ETA adaptadas ao sistema FAD e ciclos de lavagem de filtros menos frequentes. A viabilidade técnica e econômica, portanto, depende de análise individual das condições operacionais, infraestrutura e capacidade técnica dos recursos humanos disponíveis para cada ETA.

\section{CONCLUSÕES}

Os estudos de coagulação-floculação-flotação em bancada evidenciaram que a dose de coagulante e o pH se apresentaram como condições críticas à efetividade do processo. A dosagem de $8 \mathrm{mg} . \mathrm{L}^{-1}$ de CPA conduziu a ALF aos menores valores remanescentes de turbidez $(0,2 \mathrm{uT})$, cor aparente $(10 \mathrm{uC})$ e sólidos totais (20 mg. $\left.\mathrm{L}^{-1}\right)$. Os experimentos de ponto de carga zero apontaram a presença de mecanismos de coagulação aditivos à neutralização de cargas, que predominaram no sistema investigado após a adição de CPA na dose de $8 \mathrm{mg} \cdot \mathrm{L}^{-1}$.

Diante dos resultados obtidos nos estudos de FAD na unidade piloto, pode-se concluir que o emprego da técnica apresentou elevada eficiência na clarificação do resíduo. As eficiências de remoção alcançaram valores de $88 \%$ para turbidez, $86 \%$ para cor aparente, $86 \%$ para sólidos totais e $98 \%$ para sólidos suspensos totais. Todos os fatores investigados afetaram a resposta de qualidade da água, com destaque para o pH, sendo a clarificação máxima obtida na configuração com pH 6,5, dose de coagulante de 12 mg.L $\mathrm{L}^{-1}$, razão de recirculação de $10 \%$ e tempo de floculação de 15 min. Em destaque ainda, a flotação apresentou vantagens na cinética de separação comparada a sistemas de decantação. Períodos de flotação de 2 min (no mínimo 20 vezes inferiores aos dos sistemas de decantação comparados) e taxas de aplicação superiores a $12 \mathrm{~m}^{3} \cdot \mathrm{m}^{-2} \cdot \mathrm{h}^{-1}$ (contra $1,3 \mathrm{~m}^{3} \cdot \mathrm{m}^{-2} \cdot \mathrm{h}^{-1} \mathrm{em}$ sistemas de decantação) foram observados nesta investigação e destacam a forte capacidade da técnica no incremento da capacidade de tratamento de água das estações implantadas no Brasil.

Observou-se também que a FAD obteve desempenho superior à sedimentação para todos os parâmetros físico-químicos de qualidade da água investigados neste estudo. Conclui-se então que a aplicação do processo em análise reduziria a contribuição de sólidos na alimentação dos sistemas de filtros da ETA em 11,6 kg por processo unitário de lavagem, implicando o aumento da carreira de filtração em 33\%, menores custos energéticos e maior capacidade de tratamento de água nas estações.

Diante do destacado potencial para a clarificação de águas de lavagens de filtros, a coagulação-floculação-flotação apresenta-se como uma alternativa técnica com potencial de aplicação em ETA tradicionais de diferentes configurações. Naturalmente, análises técnicas e econômicas necessitam ser ajustadas à especificidade de cada realidade, especialmente na definição de custos de investimento (adaptação na infraestrutura e implantação de sistemas de geração de bolhas), operação (insumos químicos e de energia) e formação técnica dos recursos humanos envolvidos na operacionalização das unidades de tratamento de água.

\section{CONTRIBUIÇÕES DOS AUTORES}

Brazão, A. J. C.: Conceituação, Análise Formal, Investigação, Metodologia, Escrita - Primeira, Redação Escrita - Revisão e Edição. Silva, R. D. C.: Conceituação, Curadoria de Dados, Análise Formal, Investigação, Metodologia, Supervisão, Validação, Escrita - Revisão e Edição. Vicacqua, C. A.: Curadoria de dados, Investigação, Escrita - Revisão e Edição, Validação.

\section{REFERÊNCIAS}

AISSE, M. M.; JÜRGENSEN, D.; REALI, M. A. P.; PENETRA, R.; FLORENCIO, L.; SOBRINHO, P. A. Pós-tratamento de efluentes de reatores anaeróbios por sistemas de flotação. In: CHERNICHARO, C. A. L. (org.). Pós-tratamento de efluentes de reatores anaeróbios. Rio de Janeiro: FINEP/PROSAB, 2001. p. 1-34. 544 p.
ASSOCIAÇÃO BRASILEIRA DE NORMAS TÉCNICAS (ABNT). NBR 10004 Resíduos sólidos: Classificação. Rio de Janeiro: ABNT, 2004.

AZEVEDO, A.; OLIVEIRA, H.; RUBIO, J. Bulk nanobubbles in the mineral and environmental areas: Updating research and applications. Advances in Colloid and Interface Science, v. 271, 101992, set. 2019. https://doi.org/10.1016/j.cis.2019.101992 
BOURGEOIS, J.C:; WALSH, M.E.; GAGNON, G.A. Treatment of drinking water residuals: comparing sedimentation and dissolved air flotation performance with optimal cation ratios. Water Research, v. 38, n. 5, p. $1173-$ 1182, mar. 2004. https://doi.org/10.1016/j.watres.2003.11.018

BRASIL. Lei no 12.305, de 2 de agosto de 2010. Institui a Política Nacional de Resíduos Sólidos; altera a Lei no 9.605, de 12 de fevereiro de 1998; e dá outras providências. Diário Oficial [da] República Federativa do Brasil, Brasília, 2 ago. 2010. Disponível em: http://www.planalto.gov.br/ccivil_03/_ Ato2007-2010/2010/Lei/L12305.htm. Acesso em: 23 ago. 2018.

BRASIL. Ministério da Saúde. Portaria de Consolidação n 5,28 de setembro de 2017. Consolidação das normas sobre as ações e os serviços de saúde do Sistema Único de Saúde. Brasil: Ministério da Saúde, 2017.

BRATBY, J. 2006. Coagulation and flocculation in water and wastewater treatment. International Water Association (IWA), 2006.

BRATBY, J.; MARAIS, G.V. Saturator performance in dissolved-air (pressure) flotation. Water Research, v. 9, n. 11, p. 929-936, 1975. https://doi. org/10.1016/0043-1354(75)90120-7

BRITO, T.M.; DUARTE, M.A.C.; ARAÚJO, A.L.C. Caracterização quali quantitativa dos resíduos gerados em ETA de Filtração direta em escala real. In: SIMPÓSIO ITALO-BRASILEIRO DE ENGENHARIA SANITÁRIA E AMBIENTAL, 14., 2018, Foz do Iguaçu. Anais eletrônicos [...]. Foz do Iguaçu: Abes, 2018. p. 1-9.

CHAVES, K.O. Desenvolvimento e aplicação de sistema de floco-flotação por ar dissolvido para tratamento da água de lavagem do filtro da ETA gavião. 125f. Dissertação (Mestrado em Engenharia Civil) - Universidade Federal do Ceará, Fortaleza, 2012.

COSTA, E.R.; VIANA, J.H.; COELHO, E.R. Estudo da recuperação de lodo de estações de tratamento de água considerando os mecanismos de coagulação e diversos coagulantes. In: CONGRESSO BRASILEIRO DE ENGENHARIA SANITARIA E AMBIENTAL, 23., 2005, Campo Grande. Anais [.... Campo Grande: ABES, 2005.

DEOLIN, M.H.S.; FAGNANI, H.M.C.; ARROYO, P.A.; BARROS, M.A.S.D. Obtenção do ponto de carga zero de materiais adsorventes. In: ENCONTRO INTERNACIONAL DE PRODUÇÃO CIENTÍFICA, 8., 2013, Maringá. Anais eletrônicos [...]. Maringá: Cesumar, 2013. p. 1-4. Disponível em: https://www. unicesumar.edu.br/epcc-2013/trabalhos/. Acesso em: 20 ago. 2018.

DI BERNARDO, L.; DANTAS, A.D.B.; VOLTAN, P.E.N. Métodos e técnicas de tratamento de água. 3. ed. São Carlos: LDiBe, 2017.

EDZWALD, J.K.; HAARHOFF, J. Dissolved air flotation for water clarification. Nova York: McGraw-Hill, 2012.

ETCHEPARE, R.G.; OLIVEIRA, H.; NICKNIG, M.A.; AZEVEDO, A.; RUBIO, J. Nanobubbles: Generation using a multiphase pump, properties and features in flotation. Minerals Engineering, v. 112, p. 19-26, 2017. https://doi. org/10.1016/j.mineng.2017.06.020

FÉRIS, L.A.; RUBIO, J. Dissolved air flotation (DAF) performance at low saturation pressures. Filtration and Separation, v. 36, n. 9, p. 61-65, 1999. https://doi.org/10.1016/SO015-1882(99)80223-7

FITRIANTO, A.; MIDI, H. Multi-response optimization via desirability function for the black liquor DATA. Journal of Science and Technology, v. 4, n. 1, p. 91-102, 2012
FREITAS, A.G.; BASTOS, R.K.X.; BEVILACQUA, P.D.; PÁDUA, V.L.; PIMENTA, J.F.P.; ANDRADE, R.C. Recirculação de água de lavagem de filtros e perigos associados a protozoários. Engenharia Sanitária e Ambiental, Rio de Janeiro, v. 15, n. 1, p. 37-46, jan. 2010.

FREITAS, D.G. Efeitos da recirculação de água de lavagem de filtros em um sistema de filtração direta em escala de bancada. 58f. Dissertação (Mestrado em Engenharia Sanitária) - Universidade Federal do Rio Grande do Norte, Natal, 2017.

GONÇALVES, R.F.; PIOTTO, Z.C.; RESENDE, M.B. Influência dos mecanismos de coagulação da água bruta na reciclagem de coagulantes em lodos de estações de tratamento de água. In: CONGRESSO BRASILEIRO DE ENGENHARIA SANITARIA E AMBIENTAL, 19., 1997, Foz do Iguaçu. Anais [...]. Foz do Iguaçu: Abes, 1997. p 2-15.

JEONG, I.J.; KIM, K.J. An interactive desirability function method to multiresponse optimization. European Journal of Operational Research, v. 195, n. 2, p. 412-426, 2009.

LIBÂNIO, M. Fundamentos de qualidade e tratamento de água. 4. ed Campinas: Átomo, 2016.

LUSTOSA, J.B.; BRACARENSE, D.C.; CASTRO, F.M.S.; QUEIROZ, S.G.B.; SILVA, G.G. Tratamento e aproveitamento de água de lavagem de filtro em estação de tratamento de água. Revista DAE, São Paulo, v. 206, n. 2, p. 44 61, maio 2017. https://doi.org/10.4322/dae.2016.027

METCALF \& EDDY. Tratamento de efluentes e recuperação de recursos. Tradução: Ivanildo Hespanhol e José Carlos Mierzwa. 5. ed. Porto Alegre: AMGH, 2016

METCALF \& EDDY. Wastewater engineering: treatment and reuse. 4. ed. Nova York: McGraw Hill, 2003. 1819 p.

RITCHER, C.A. Água: métodos e tecnologia de tratamento. São Paulo: Blucher, 2009.

RODRIGUES, C.O. Mecanismos de floculação com polímeros hidrossolúveis, geração de flocos aerados, floculação em núcleos de bolhas floculantes e aplicações na separação de partículas modelos por flotação. 242f. Tese (Doutorado em Engenharia de Minas, Metalúrgica e de Materiais) Universidade Federal do Rio Grande do Sul, Porto Alegre, 2010.

RODRIGUES, R.T. Desenvolvimento da técnica LTM-BSizer para a caracterização de bolhas e a avaliação de parâmetro no processo de flotação. 132f. Tese (Doutorado em Engenharia de Minas, Metalúrgica e de Materiais) - Universidade Federal do Rio Grande do Sul, Porto Alegre, 2004

SILVA, R.D.R. Interações de ions sulfato com sais de aluminio em soluções ácidas. Estudos básicos e aplicações ambientais. 125f. Tese (Doutorado em Engenharia de Minas, Metalúrgica e de Materiais) - Universidade Federal do Rio Grande do Sul, Porto Alegre, 2011.

ŞIMŞEK, B.; TANSEL IÇ, Y.; ŞIMŞEK, E.H. A full factorial design based desirability function approach for optimization of properties of $C 40 / 50$ concrete class. Mathematical and Computational Applications, v. 18, n. 3, p. 330-339, 2013. https://doi.org/10.3390/mca18030330

TESSELE, F; MONTEGGIA, L.O.; NEDER, K.D;; CASTRO JUNIOR, J.M.; ROSA, J.J. Polimento de efluentes de lagoa de estabilização por flotação a ar dissolvido. In: CONGRESSO BRASILEIRO DE ENGENHARIA SANITÁRIA E AMBIENTAL, 23., 2005, Campo Grande. Anais [...]. Campo Grande: Abes, 2005. p. 1-4. 
UNITED STATES ENVIRONMENTAL PROTECTION AGENCY (USEPA). Filter backwash recycling rule. Technical guidance manual. Washington, D.C.: USEPA, 2002. 166 p. Disponível em: https://bityli.com/7FGfv. Acesso em: 23 jul. 2018.
WIMMER, A. C. S. Aplicação do processo eletrolítico no tratamento de efluentes de uma indústria petroquímica. 195f. Dissertação (Mestrado em Ciência dos Materiais e Metalurgia) - Pontifícia Universidade Católica, Rio de Janeiro, 2008. 